Article

\title{
Critical Success Factors of the Reliability-Centred Maintenance Implementation in the Oil and Gas Industry
}

\author{
Masoomeh Zeinalnezhad ${ }^{1}$, Abdoulmohammad Gholamzadeh Chofreh ${ }^{2, * \mathbb{D}}$, Feybi Ariani Goni ${ }^{2}$ \\ and Jiří Jaromír Klemeš ${ }^{2} \mathbb{D}$ \\ 1 Department of Industrial Engineering, West Tehran Branch, Islamic Azad University, \\ Tehran 1468763785, Iran; zeinalnezhad.m@wtiau.ac.ir \\ 2 Sustainable Process Integration Laboratory-SPIL, NETME Centre, Faculty of Mechanical Engineering, \\ Brno University of Technology_VUT Brno, Technická 2896/2, 61669 Brno, Czech Republic; \\ goni@fme.vutbr.cz (F.A.G.); jiri.klemes@vutbr.cz (J.J.K.) \\ * Correspondence: chofreh@fme.vutbr.cz
}

Received: 5 August 2020; Accepted: 18 September 2020; Published: 23 September 2020

\begin{abstract}
Reliability-Centred Maintenance (RCM) is a strategic process to improve the maintenance planning of companies which contributes to sustainable production. This method has been applied by numerous industries to achieve an efficient maintenance process, but many have not fully completed their goals. The reason for this failure is that RCM implementation is complex, and organisations need to have adequate preparations before they implement it. In the pre-implementation phase, it is necessary to know the number of Critical Success Factors (CSFs) as a critical measure for implementing the RCM method successfully. Therefore, it is important for practitioners to apply a symmetric mechanism involving fuzzy systems to achieve the desired RCM implementation. There are a limited number of studies that have observed these factors regarding the characteristics of oil and gas companies, especially in the pre-implementation phase. Addressing RCM pre-implementation issues is of high importance from the economic perspective of sustainability for oil and gas organisations. The objective of this study is to investigate significant items in RCM pre-implementation through a combination of quantitative and qualitative analyses. The Nominal Group Technique (NGT) method is applied by gaining the opinion of experts to determine the factors and prioritising them using mathematical modelling. A group of related experts from the oil and gas industry were initially interviewed and surveyed to determine the critical success factors. These identified factors were then analysed using quantitative analysis to identify the important degrees and scored using Fuzzy Analytic Network Process (FANP). Fifteen major factors affecting the criticality of successful RCM implementation have been identified and prioritised, based on their weights. The model proposed in this study could be used as a guideline for assessing CSFs in other countries. To apply the proposed model in different contexts, it needs to be modified according to the needs, policies, and perspectives of each country.
\end{abstract}

Keywords: reliability centred maintenance (RCM); critical success factors (CSFs); nominal group technique (NGT); fuzzy analytic network process (FANP); oil and gas industry

\section{Introduction}

Managers are now looking for various maintenance disciplines to rationalise the achievement of their business in the face of ongoing challenges to improve plant reliability at a lower cost [1]. In this regard, Reliability Centred Maintenance (RCM) is defined as a systematic methodology for the optimisation and development of the maintenance requirements of a physical resource [2]. It has 
been recently found to be the most efficient strategy in comparison with the existing supervision of maintenance strategies [2]. This method has been successfully applied for more than $30 \mathrm{y}$ in several industries, such as aircraft, military forces, nuclear power, and oil and gas companies [3]. Research has confirmed that the RCM method is imperative to reduce maintenance costs and improve the effectiveness of the maintenance systems [4]. It enables the organisation to minimise maintenance duration and create a safe environment, which has been an issue of concern to manufacturers [5]. An application of the RCM method is imperative for organisations to optimise their maintenance activities and to develop a cost-effective method for managing their maintenance procedures [6]. Wang et al. [7] concluded that the system operates under a performance-based contract. RCM helps service providers to increase profits and improve system performance at lower costs. Similar to them, Ma et al. [8] confirmed the maintenance cost is minimised via RCM implementation in their case study, namely, a warm standby cooling system.

Especially in the oil and gas industry, there is an ongoing emphasis on cost management, where prices are very flexible and vulnerable to changes in supply and demand [9]. Oil and gas plants produce a wide range of products used as chemicals and fuels, so, maintenance activities within them remarkably affect their productivity. The use of RCM can help organisations develop a systematic maintenance program, meeting these requirements in a cost-effective manner [9].

The RCM methods have a close link to sustainability [10]. An organisation that strives towards effective sustainability requires effective RCM practices and technologies [11]. However, the organisation still faces difficulty and even failure during the RCM implementation. Plucknette [12] stated that based on the survey of more than 250 companies, over $85 \%$ of the RCM analysis had not been completely implemented. While the fundamental notion of the RCM method is simple, its implementation is tremendously complicated [13].

An organisation should have effective preparations before they transform their conventional maintenance systems towards RCM [14]. One of the essential processes in the pre-implementation phase is considering several Critical Success Factors (CSFs), used as an important measure to implement the RCM methods successfully. Practitioners often ignore this preparation phase. This problem also emerged in Iranian manufacturing organisations. Numbers of companies in Iran have considered the vital role of the RCM to enhance the effectivity and efficiency of the equipment and machinery [15]. This approach has not been applied effectively in Iranian oil industries as it needs proper preparation for planning [16]. RCM implementation is complex, and organisations need to have adequate preparations before they implement the RCM methods. In the pre-implementation phase, the number of CSFs, as a key measure to implement the RCM methods successfully, is necessary. The practitioners often skip this pre-implementation phase. As a result, the majority of the manufacturing companies face many problems during the implementation process since they do not have a sufficient preparation plan.

There are a small number of RCM researches that aimed to identify and prioritise the critical factors for implementing RCM regarding the characteristics of oil and gas organisations [16]. The majority of them focused on the implementation process without considering the important processes in the pre-implementation phase. To fill this gap, this study is conducted to identify the CSFs which are imperative to be addressed by oil and gas organisations using symmetric mechanism involving fuzzy systems to achieve the desired RCM implementation. It is done using the Nominal Group Technique (NGT) and Fuzzy Analytic Network Process (FANP). The Analytic Network Process (ANP) is generally used to rank the decisions without creating assumptions about the unidirectional hierarchy relationship between decision levels. As ANP lacks a comprehensive consideration of human intelligence in modelling, fuzzy models have been applied as they have better compatibility with linguistic explanations and are often ambiguous for making long-term predictions and for making real-world decisions [17]. Fuzzy logic has been widely applied in numerous fields such as optimisation, systems engineering, and image processing [18].

The structure of this paper is organised as follows. Section 2 provides an analysis of related studies, which culminates with the identification of the knowledge gap. Section 3 explains the research 
process of the present study. Section 4 presents the data analysis and discussion of the research findings. Section 5 concludes the study and recommends the numbers of potential research directions.

\section{Literature Review}

A concept that has changed in the Prognostics and Health Management (PHM) implementation from seeking the remaining useful life to determining extendable useful life [19]. Research in RCM area has been rapidly growing these years because of increasing challenges and expectations of maintenance [14]. The topic in the RCM area includes RCM implementation, optimisation of the method, integration between the RCM with other techniques, risk reduction, and evaluation of the RCM failures [2]. This study categorised the topics into three phases: RCM pre-implementation, implementation and post-implementation, as shown in Figure 1.

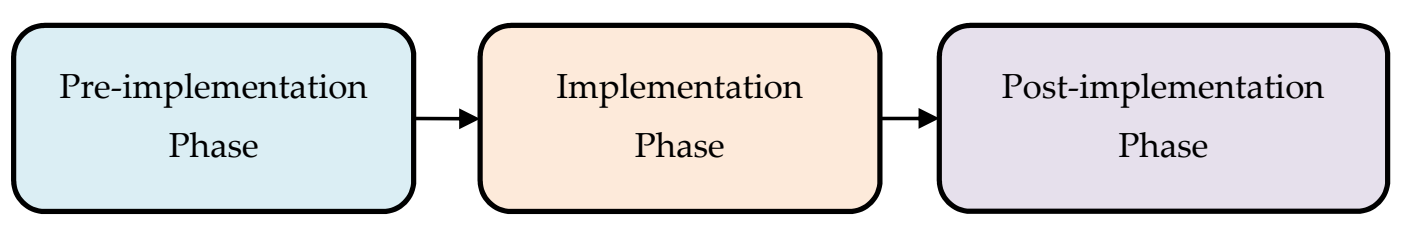

Figure 1. Reliability Centred Maintenance (RCM) implementation phases.

Tang et al. [14] mentioned that the screening phase is one of the critical steps of the RCM implementation, which is named as the pre-implementation phase, as provided in Figure 1. This phase of RCM focuses on assessing and providing the necessary preparations before RCM implementation. There is rarely a systematic operation method to identify the CSFs of RCM pre-implementation. In their research, Tang et al. [14] presented a framework for the identification of the maintenance of significant items through a mixture of quantitative and qualitative analysis.

In the power system industry, Afzali et al. [20] presented new weighted importance (WI) reliability index model. They proposed an applicable method to rank the components of the RCM distribution system for RCM at two different levels. First, the sample feeder substation feeder is ranked for the RCM action. The sample feeder component is then rated for the RCM action. In another study, Alvarez-Alvarado and Jayaweer [21] found RCM as a popular method in that industry. They proposed an innovative smart maintenance model through three main concepts, namely Markov chains to describe the reliability of component, Fuzzy logic to determine the operational risk of component, and maintenance exertion degree to define the impact of maintenance over the component failure rate. In electric power distribution systems, Piasson et al. [22] proposed a model to optimise the RCM implementation by reducing the maintenance costs and increasing the index of systems reliability. They evaluated the reliability indices of the components using a fuzzy inference system and proposed a Non-Dominated Sorting Genetic Algorithm II (NSGA-II) algorithm to resolve multi-objective models that provide an optimised Pareto frontier. Yssaad and Abene [23] optimised the application of RCM using reliability, availability, and maintainability studies to advance the power distribution systems.

Zakikhani et al. [13] developed a framework for maintenance scheduling for the external corrosion of gas transmission pipelines using the RCM planning technique. This framework is designed based on the pipeline reliability outline obtained from the Monte Carlo simulation. They discovered that the maintenance method developed only relied on the consideration of reliability, cost, and condition levels as the criteria for maintenance decisions and discounted the significance of continues action and accessibility.

Rahmati et al. [15] proposed a new stochastic RCM procedure in a new multi-objective joint maintenance and production planning problem. They used four multi-objective simulation-based optimisation algorithms to resolve the issues as they belong to the Non-deterministic Polynomial-time Hardness (NP-Hard) class of optimisation problems. These four multi-objective simulations are the multi-objective biogeography based optimisation algorithm, the Pareto envelope-based selection algorithm, a new version of the Non-Dominated Sorting Genetic Algorithm (NSGAIII), 
and multi-objective evolutionary algorithm based on decomposition. A new combined visualisation method using the Gant chart is also projected to discuss the entire RCM scheme in a systematic manner.

Piechnicki et al. [24] designed a conceptual framework that adapts tacit and explicit information from maintenance functions. Their study generates a new knowledge base that is used to analyse and improve decisions on implementing customised RCM models. They used multi-criteria decision making analysis techniques to support decisions in the RCM implementation stage. Data-driven prognostic approaches are also studied for equipment maintenance [25].

Tang et al. [14] developed a framework to identify the critical maintenance items in RCM using qualitative and quantitative analysis to advance the effectiveness and efficiency of the maintenance policy. They used the multiple risk matrix, Failure Mode and Effects Analysis (FMEA), Analytic Hierarchy Process (AHP), and Fuzzy Borda Count methods to do their research. Reliability-based maintenance modelling was also employed to enhance the rolling stock objectives of manufacturers [26]. Similarly, Yavuz [27] confirmed the effectiveness of the RCM approach in the food industry.

Regarding the characteristics of oil and gas organisations, there are few scientific maintenance studies which are explicitly conducted to improve the reliability of the refinery unit [28]. Petrochemical industries are classified as high-risk companies, and the application of suitable maintenance strategies is imperative to reduce costs, to improve quality, minimise equipment downtime, and increase productivity [29]. The components of refinery equipment are explosive, flammable, and toxic, so it is necessary to carry out an effective maintenance plan to ensure safety and reliability [28]. The oil and gas industry has still an essential role in the economic growth of most developing countries [30], and the success or failure of maintenance programs may depend on adequate identification and consideration of CSFs.

The literature review confirmed that, when paired with RCM policy, maintenance tasks in the oil and gas industry will perform in an efficient, reliable, cost-effective, and safe manner [9]. There is a variety of research in the RCM subject [31]; however, there are fewer studies that concern the preliminary implementation of the RCM, such as the determination of important factors of success, particularly in oil and gas companies. These factors are the core elements of a maintenance plan that it views as the most important task before the RCM implementation. Practitioners in organisations need to evaluate these factors to accomplish successful RCM implementation and reduce failure risks. This knowledge gap motivates the present study to identify numbers of CSFs as a key measure to achieve successful implementation of the RCM. The identification uses the Fuzzy Analytic Network Process (FANP) to address the uncertainty and imprecision in the prioritisation process.

\section{Materials and Methods}

A Nominal Group Technique (NGT), which involves qualitative and quantitative analysis [32], is applied to collect and analyse the data. This technique is chosen because it is a structured technique for group brainstorming, that encourages contributions from everyone and facilitates quick agreement on the relative importance of issues [33]. The experts should make their decision using the votes and opinions of everyone.

There are two main phases of our research methodology: (i) Determining the success factors of the RCM implementation, and, (ii) Prioritising them. A schematic overview of the research method in this study is provided in Figure 2. A nominal group technique is adopted to refine the factors and make pairwise comparisons, and the fuzzy ANP method is used to evaluate the relative importance and prioritise the identified success factors. 
Phase 1. Determination of the Critical Success Factors (CSFs)

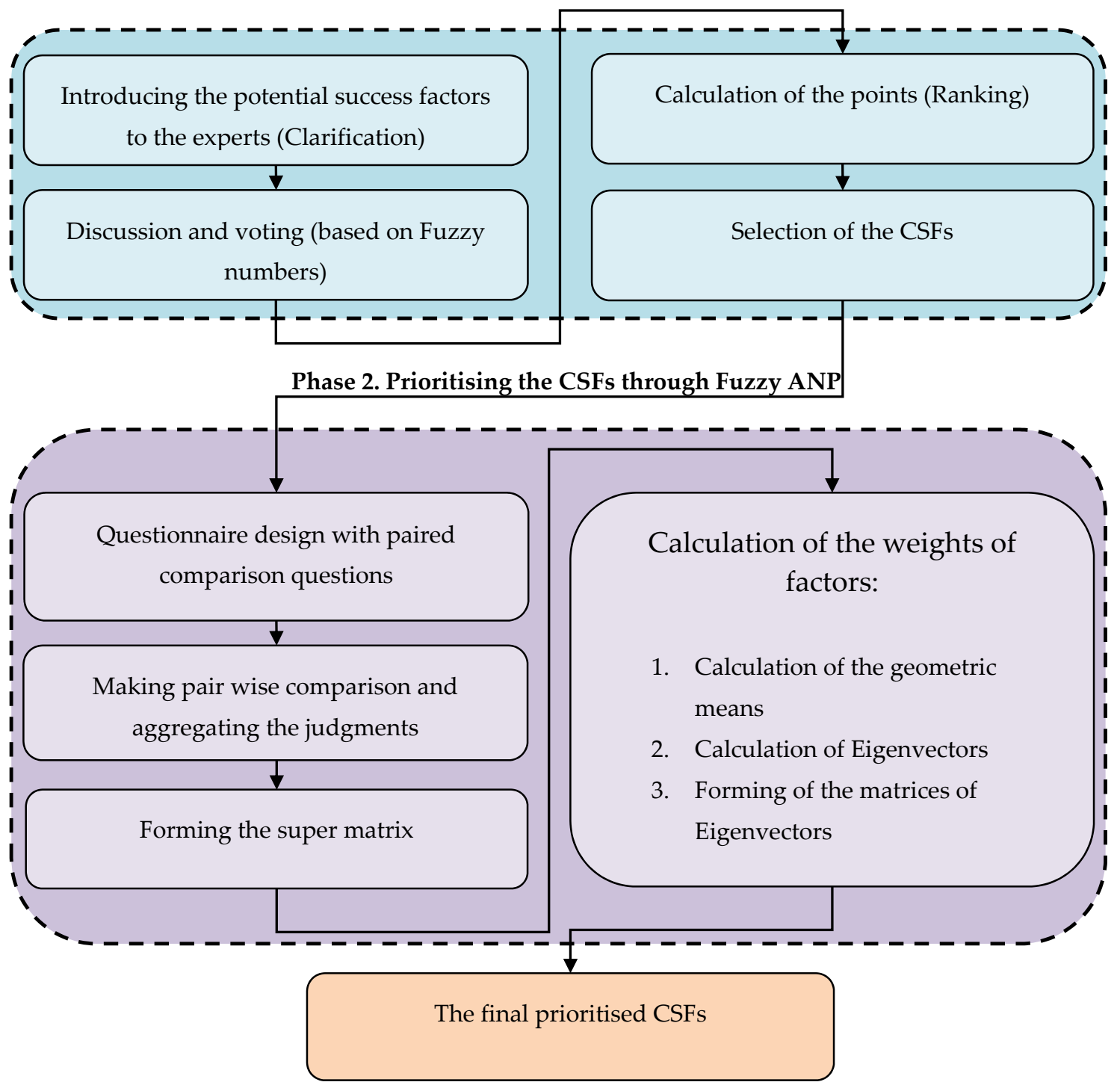

Figure 2. Research flow of the study

As shown in Figure 2, a preliminary list of success factors, consisting of 20 items, was identified based on a review of the literature and surveys. These success factors are then introduced to the RCM team, which includes ten experts and managers from technical and engineering departments, the strategic planning and development deputy, the support and logistics deputy, and the human resources, deputy. This team has been selected at the discretion of the managers of Persian Gulf Star Oil Company. It involves people who have been responsible for the maintenance of company and repair program.

The initial factors were validated, modified and scored by team members through discussion and voting, which resulted in 15 CSFs. These CSFs were then prioritised using fuzzy ANP, as shown in phase 2. The Analytic Network Process (ANP) is an extension of the analytical hierarchy process which allows analysis of complex systems. As there are limitations in the determination of success factors, to make better decisions in this process, the weights of factors are determined by using fuzzy ANP. In FANP, the importance weights of criteria can be evaluated using linguistic values represented by fuzzy numbers. This technique enables one to overcome uncertainties and inaccuracies in the priority setting process. 
In phase 2, a questionnaire for paired comparisons is developed. The RCM team members filled in the surveys and the aggregated pairwise comparison matrices are calculated based on their responses. To obtain the final priorities in a system that is affected by internal dependence, local priority vectors are entered in proportion to the columns of the matrix, which is known as the supermatrix. Based on this matrix, the weights of factors were calculated, through four steps and the critical factors influencing the success of RCM pre-implementation are prioritised.

\section{Results}

According to Figure 2, this study was completed in two main phases, namely, determination of the CSFs and prioritising them through the formation of the supermatrix and calculation of the weight of factors using FANP. The calculations are made, and the results obtained from the various stages of the research are presented in this section.

\subsection{Determination of the Critical Success Factors}

The determination of the CSFs was done via discussions with a group of experts through the NGT. The descriptive statistics related to the identified factors are summarised in Table 1 . These values were calculated based on the analysis of the data gathered by the questionnaires.

Table 1. The descriptive statistics

\begin{tabular}{cccccccccc}
\hline Symbol & Sum & Mean & Mode & Max & Min & Standard Error & Variance & Skewness & Kurtosis \\
\hline F1 & 78 & 7.8 & 7 & 9 & 7 & 0.75 & 0.56 & 0.41 & -1.07 \\
F2 & 43 & 4.3 & 4 & 6 & 3 & 0.90 & 0.81 & 0.23 & -0.35 \\
F3 & 81 & 8.1 & 8 & 9 & 7 & 0.70 & 0.49 & -0.17 & -0.73 \\
F4 & 79 & 7.9 & 7 & 10 & 7 & 1.04 & 1.09 & 0.86 & -0.52 \\
F5 & 65 & 6.5 & 6 & 8 & 5 & 0.81 & 0.65 & 0.00 & 0.11 \\
F6 & 81 & 8.1 & 8 & 10 & 7 & 0.94 & 0.89 & 0.61 & -0.16 \\
F7 & 61 & 6.1 & 7 & 7 & 5 & 0.83 & 0.69 & -0.22 & -1.73 \\
F8 & 59 & 5.9 & 6 & 8 & 5 & 0.94 & 0.89 & 1.08 & 0.91 \\
F9 & 43 & 4.3 & 4 & 5 & 3 & 0.64 & 0.41 & -0.43 & -0.28 \\
F10 & 77 & 7.7 & 7 & 10 & 6 & 1.10 & 1.21 & 0.73 & 0.51 \\
F11 & 71 & 7.1 & 7 & 8 & 6 & 0.70 & 0.49 & -0.17 & -0.73 \\
F12 & 83 & 8.3 & 9 & 10 & 7 & 1.00 & 1.01 & -0.04 & -1.24 \\
F13 & 47 & 4.7 & 5 & 6 & 3 & 0.90 & 0.81 & -0.23 & -0.35 \\
F14 & 55 & 5.5 & 6 & 7 & 3 & 1.20 & 1.45 & -0.82 & 0.25 \\
F15 & 61 & 6.1 & 5 & 8 & 5 & 1.04 & 1.09 & 0.39 & -1.24 \\
F16 & 63 & 6.3 & 5 & 8 & 5 & 1.19 & 1.41 & 0.14 & -1.77 \\
F17 & 37 & 3.7 & 2 & 7 & 2 & 1.79 & 3.21 & 1.16 & 0.17 \\
F18 & 52 & 5.2 & 5 & 6 & 4 & 0.60 & 0.36 & -0.13 & 0.18 \\
F19 & 39 & 3.9 & 2 & 9 & 1 & 2.62 & 6.89 & 0.92 & -0.67 \\
F20 & 69 & 6.9 & 7 & 10 & 5 & 1.58 & 2.49 & 0.56 & -0.04 \\
\hline
\end{tabular}

Sum: Summation function; Mean: The average of the numbers; Mode: The number that appears most frequently in a data set; Max: Maximum function; Min: Minimum function.

The symbols, F1 to F10, are related to the "Items", introduced in Table 2. Small values of skewness and kurtosis indicate that in most cases, the data have a normal distribution [34]. The items were scored using linguistic values represented by fuzzy numbers. The linguistic scales and their fuzzy levels in this study are developed in the following Table 3. 
Table 2. The scored items for successful implementation of RCM.

\begin{tabular}{|c|c|c|c|c|}
\hline No. & Status of Item & Score & Items & Symbol \\
\hline 1 & Accepted & 78 & Skilled human resources & F1 \\
\hline 2 & Rejected & 43 & $\begin{array}{c}\text { Needs assessment for CMMS (Computerized } \\
\text { Maintenance Management System) }\end{array}$ & F2 \\
\hline 3 & Accepted & 81 & Sufficient budget & F3 \\
\hline 4 & Accepted & 79 & $\begin{array}{l}\text { Awareness of the need for improved } \\
\text { maintenance programs in the organisation }\end{array}$ & F4 \\
\hline 5 & Accepted & 65 & $\begin{array}{l}\text { Technical knowledge and using the best way } \\
\text { to select critical equipment for RCM analysis }\end{array}$ & F5 \\
\hline 6 & Accepted & 81 & Sufficient time & F6 \\
\hline 7 & Accepted & 61 & Training & F7 \\
\hline 8 & Accepted & 59 & RCM knowledge among managers & F8 \\
\hline 9 & Rejected & 43 & Shortage of the main parts of the equipment & F9 \\
\hline 10 & Accepted & 77 & $\begin{array}{l}\text { Understand the need to establish an RCM } \\
\text { strategy }\end{array}$ & F10 \\
\hline 11 & Accepted & 71 & $\begin{array}{c}\text { Paying attention to maintenance strategies to } \\
\text { reduce costs }\end{array}$ & F11 \\
\hline 12 & Accepted & 83 & Motivation among staff & F12 \\
\hline 13 & Rejected & 47 & Economic sanctions & F13 \\
\hline 14 & Accepted & 55 & Teamwork & F14 \\
\hline 15 & Accepted & 61 & RCM knowledge among staffs & F15 \\
\hline 16 & Accepted & 63 & Accessibility to machinery information & F16 \\
\hline 17 & Rejected & 37 & Safety and environmental issues & F17 \\
\hline 18 & Accepted & 52 & Capability to change the design of equipment & F18 \\
\hline 19 & Rejected & 39 & Responsiveness of the top management & F19 \\
\hline 20 & Accepted & 69 & Staffs' commitment & F20 \\
\hline
\end{tabular}

Table 3. The linguistic scales for relative importance.

\begin{tabular}{ccc}
\hline Code & Linguistic Scale & Triangular Fuzzy Scale \\
\hline 1 & Complete equal importance & $(1,1,1)$ \\
2 & Nearly equal importance & $(0.5,1,1.5)$ \\
3 & Low importance & $(1,1.5,2)$ \\
4 & High importance & $(1.5,2,2.5)$ \\
5 & Very high importance & $(2,2.5,3)$ \\
6 & Completely high importance & $(2.5,3,3.5)$ \\
\hline
\end{tabular}

The calculated values of the scores related to all 20 factors are given in Table 2. Those that scored less than 50 points were eliminated, while the items receiving more than 50 points are considered as the CSFs.

As provided in Table 2, fifteen success factors scored more than 50, and five factors had a score of less than 50. The final fifteen CFSs for pre-implementation of RCM are listed as follows:

1. Skilled human resources

2. Sufficient budget

3. Awareness of the need for improved maintenance programs in the organisation

4. Technical knowledge and using the best way to select critical equipment for RCM analysis

5. Sufficient time

6. Training

7. RCM knowledge among managers

8. Understand the need to establish an RCM strategy

9. Paying attention to maintenance strategies to reduce costs

10. Motivation among staffs

11. Teamwork 
12. RCM knowledge among staff

13. Accessibility to machinery information

14. Capability to change the design of equipment

15. Staffs' commitment

\subsection{Prioritising the CSFs through Fuzzy ANP}

A questionnaire with paired comparison questions was designed, validated, and distributed among the experts to rank the identified CSFs. The pairwise comparisons matrix based on the collected data was formed. A summary of the supermatrix analysis for obtaining the weights of factors was derived, based on the work of Gogus and Boucher [35]. Each of the local priority vectors was entered as a part of the matrix column, known as supermatrix. This partitioned matrix represents the effect of the element to the left of the matrix on the element at the top of the matrix. The supermatrix serves as a unifying framework [36]. Its general form is shown in Figure 3.

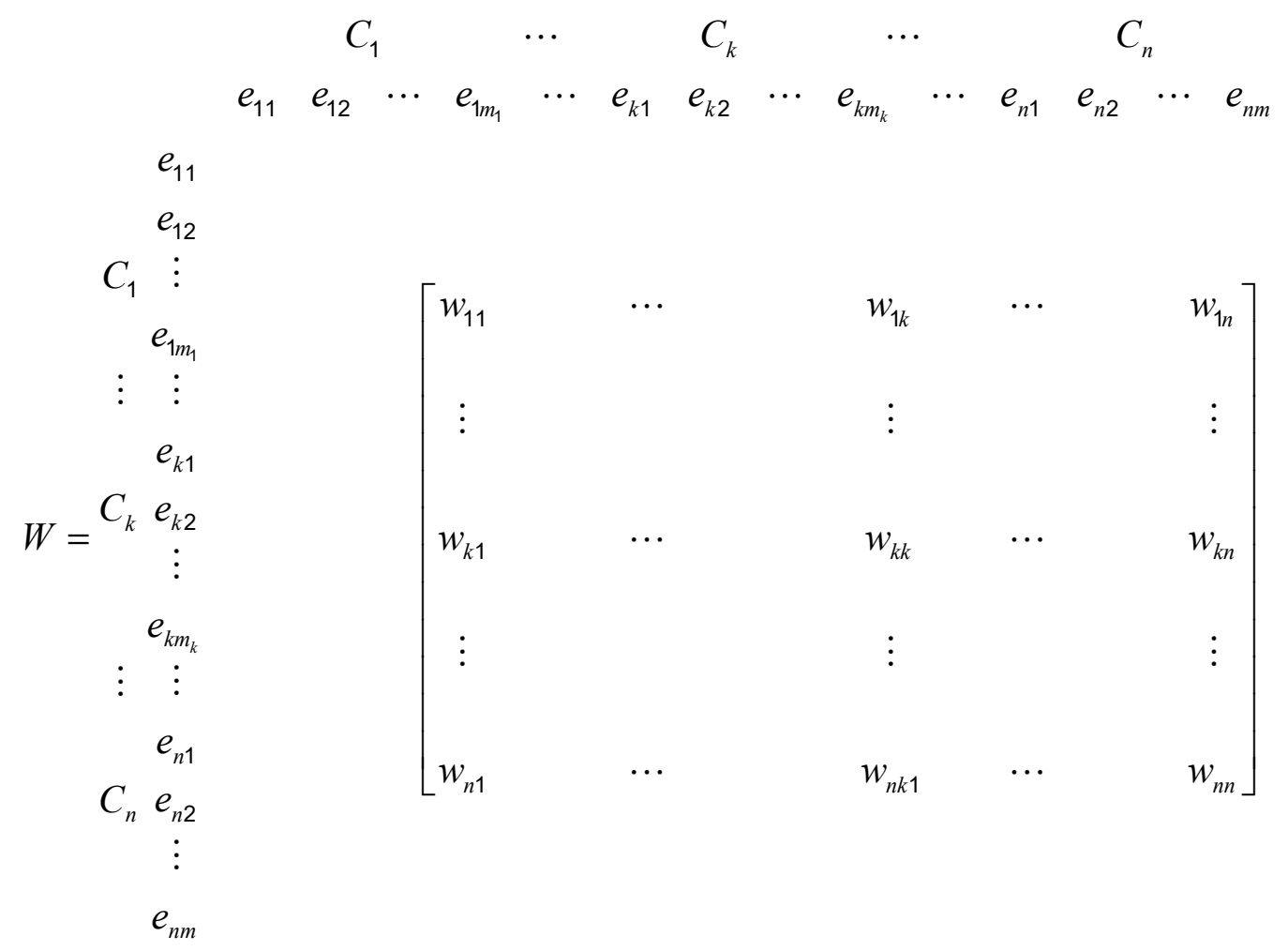

Figure 3. A generalised supermatrix (adopted from Asan et al. [36]).

In Figure $3, C_{m}$ means the $m$ th cluster with $n_{m}$ elements symbolised as $e_{m 1}, e_{m 2}, \ldots, e_{m n}$, where $e_{m n}$ represents the nth element in the $m$ th cluster. $W_{\mathrm{ij}}$ is a block matrix consisting of principal eigenvectors representing the influence of the elements in the ith cluster on the elements in the jth cluster.

\subsubsection{Calculation of the Geometric Means}

The geometric means of the paired wise comparisons are presented in Table 4. They were obtained via calculation of the square root of multiplying of the high and low limits of triangular numbers, namely, $A^{g}=\sqrt{a_{i j u} \cdot a_{i j l}}$. 
The weight vectors of each matrix should be calculated using $w^{m}=\left[w_{i}^{m}\right]$ and $w^{g}=\left[w_{i}^{g}\right]$ by considering the Equations (1) and (2), which are developed in this study.

$$
\begin{gathered}
w_{i}^{m}=\frac{1}{n} \sum_{j=1}^{n} \frac{a_{i j m}}{\sum_{i=1}^{n} a_{i j m}} \\
w_{i}^{g}=\frac{1}{n} \sum_{j=1}^{n} \frac{\sqrt{a_{i j u} \cdot a_{i j l}}}{\sum_{i=1}^{n} \sqrt{a_{i j u} \cdot a_{i j l}}}
\end{gathered}
$$

For this matrix, the Consistency Ratios (CR) obtained were 0.037 and 0.096 , which are less than 0.1 , meaning the matrix is compatible.

\subsubsection{Calculation of the Eigenvectors}

The Eigenvectors were calculated using the logarithmic method of the least squares, which is shown in Equation (3).

$$
\begin{gathered}
w_{k}^{s}=\frac{\left(\prod_{j=1}^{n} a_{k j}^{s}\right)^{\frac{1}{n}}}{\sum_{i=1}^{n}\left(\prod_{j=1}^{n} a_{i j}^{m}\right)^{\frac{1}{n}}}, \quad s \in\{l, m, u\} \\
\widetilde{w}_{k}=\left(w_{k^{\prime}}^{l}, w_{k}^{m}, w_{k}^{u}\right) \quad k=1,2,3, \ldots, n
\end{gathered}
$$

The values of Eigenvectors are presented in the last row of Table 3.

\subsubsection{Forming of the Matrices of Eigenvectors}

Based on the Eigenvectors values, the Principal Eigenvectors matrix is calculated in this study and presented in Table 5 .

Table 4 contains Eigenvectors that show internal dependencies between factors. If there is no relationship between the two elements, the value of $(0,0,0)$ is considered.

\subsubsection{Calculation of the Final Weights}

For calculating the final weight of items for each surface $\left(\mathrm{W}_{\mathrm{i}}^{*}\right)$, the following formulas were applied.

$$
\begin{gathered}
W_{i}^{*}=W_{i i} \times W_{i(i-1)} \times W_{i-1}^{*} \\
W_{i}^{*}=I \times W_{i(i-1)} \times W_{i-1}^{*}
\end{gathered}
$$

According to Equations (4) and (5), the final weights were calculated, and the results are shown in Table 6. 
Table 4. The geometric means of pairwise comparisons and Eigenvectors

\begin{tabular}{|c|c|c|c|c|c|c|c|c|c|c|c|c|c|c|c|c|}
\hline & F1 & F3 & F4 & F5 & F6 & F7 & F8 & F10 & F11 & F12 & F14 & F15 & F16 & F18 & F20 & Eigenvector \\
\hline F1 & $(1,1,1)$ & $(0.5,0.667,1)$ & $(0.4,0.5,0,067)$ & $(0.4,0.5,0.667)$ & $(1,1.5,2)$ & $(0.5,1,1.5)$ & $(1,1.5,2)$ & $(0.5,1,1.5)$ & $(0.5,1,1.5)$ & $(1,1.5,2)$ & $(1.5,2,2.5)$ & $(1,1.5,2)$ & $(0.5,1,1.5)$ & $(1.5,2,2.5)$ & $(0.5,1,1.5)$ & $(0.046,0.07,0.096)$ \\
\hline F3 & $(1,1.5,2)$ & $(1,1,1)$ & $(0.5,0.667,1)$ & $(0.5,0.667,1)$ & $(1.5,2,2.5)$ & $(0.5,1,1.5)$ & $(0.5,1,1.5)$ & $(0.5,1,1.5)$ & $(1,1.5,2)$ & $(1.5,2,2.5)$ & $(0.5,1,1.5)$ & $(0.5,1,1.5)$ & $(0.5,1,1.5)$ & $(1,1.5,2)$ & $(0.5,1,1.5)$ & $(0.045,0.073,0.102)$ \\
\hline F4 & $(1.5,2,2.5)$ & $(1,1.5,2)$ & $(1,1,1)$ & $(1,1.5,2)$ & $(1.5,2,2.5)$ & $(1.5,2,2.5)$ & $(1,1.5,2)$ & $(1,1.5,2)$ & $(1.5,2,2.5)$ & $(2,2.5,3)$ & $(1,1.5,2)$ & $(0.5,1,1.5)$ & $(1,1.5,2)$ & $(2,2.5,3)$ & $(0.5,1,1.5)$ & $(0.072,0.104,0.134)$ \\
\hline F5 & $(1.5,2,2.5)$ & $(1,1.5,2)$ & $(0.5,0.667,1)$ & $(1,1,1)$ & $(0.5,1,1.5)$ & $(1,1.5,2)$ & $(1.5,2,2.5)$ & $(1.5,2,2.5)$ & $(1.5,2,2.5)$ & $(2,2.5,3)$ & $(1,1.5,2)$ & $(1,1.5,2)$ & $(0.5,1,1.5)$ & $(2,2.5,3)$ & $(1,1.5,2)$ & $(0.069,0.098,0.128)$ \\
\hline F6 & $(0.5,0.667,1)$ & $(0.4,0.5,0.667)$ & $(0.4,0,0,0,0.667)$ & $(0.667,1,2)$ & $(1,1,1)$ & $(0.4,0.5,0.667)$ & $(1,1.5,2)$ & $(0.5,0.667,1)$ & $(0.5,0.667,1)$ & $(0.667,1,2)$ & $(1,1.5,2)$ & $(0.4,0.5,0.667)$ & $(0.333,0.4,0.5)$ & $(2,2.5,3)$ & $(0.667,1,2)$ & $(0.04,0.053,0.075)$ \\
\hline F7 & $(0.667,1,2)$ & $(0.667,1,2)$ & $(0.4,0.5,0.667)$ & $(0.5,0.667,1)$ & $(1.5,2,2.5)$ & $(1,1,1)$ & $(0.5,1,1.5)$ & $(0.5,1,1.5)$ & $(0.5,0.667,1)$ & $(1,1.5,2)$ & $(1.5,2,2.5)$ & $(1.5,2,2.5)$ & $(1,1.5,2)$ & $(2,2.5,3)$ & $(1,1.5,2)$ & $(0.055,0.078,0.109)$ \\
\hline F8 & $(0.5,0.667,1)$ & $(0.667,1,2)$ & $(0.5,0.667,1)$ & $(0.4,0.5,0.667)$ & $(0.5,0.667,1)$ & $(0.667,1,2)$ & $(1,1,1)$ & $(0.4,0.5,0.667)$ & $(0.667,1,2)$ & $(0.5,0.667,1)$ & $(1,1.5,2)$ & $(0.667,1,2)$ & $(0.5,1,1.5)$ & $(0.5,1,1.5)$ & $(0.5,1,1.5)$ & $(0.037,0.055,0.084)$ \\
\hline F10 & $(0.667,1,2)$ & $(0.667,1,2)$ & $(0.5,0.667,1)$ & $(0.4,0.5,0.667)$ & $(1,1.5,2)$ & $(0.667,1,2)$ & $(1.5,2,2.5)$ & $(1,1,1)$ & $(1,1.5,2)$ & $(0.5,1,1.5)$ & $(0.5,1,1.5)$ & $\begin{array}{l}0.5,0.667,1) \\
\end{array}$ & $(0.5,1,1.5)$ & $(0.5,1,1.5)$ & $(0.5,0.667,1)$ & $(0.042,0.063,0.094)$ \\
\hline F11 & $(0.667,1,2)$ & $(0.5,0.667,1)$ & $(0.4,0.5,0.667)$ & $(0.4,0.5,0.667)$ & $(1,1.5,2)$ & $(1,1.5,2)$ & $(0.5,1,1.5)$ & $(0.5,0.667,1)$ & $(1,1,1)$ & $(0.5,1,1.5)$ & $(0.5,0.667,1)$ & $(0.5,0.667,1)$ & $(1,1.5,2)$ & $(0.5,1,1.5)$ & $(0.5,0.667,1)$ & $(0.039,0.056,0.08)$ \\
\hline F12 & $(0.5,0.667,1)$ & $(0.4,0.5,0.667)$ & $(0.333,0.4,0.5)$ & $(0.333,0.4,0.5)$ & $(0.5,1,1.5)$ & $(0.5,0.667,1)$ & $(1,1.5,2)$ & $(0.667,1,2)$ & $(0.667,1,2)$ & $(1,1,1)$ & $(1,1.5,2)$ & $(1,1.5,2)$ & $(1,1.5,2)$ & $(1,1.5,2)$ & $(1.5,2,2.5)$ & $(0.045,0.062,0.087)$ \\
\hline F14 & $(0.4,0.5,0.667)$ & $(0.667,1,2)$ & $(0.5,0.667,1)$ & $(0.5,0.667,1)$ & $\begin{array}{l}0.5,0.667,1) \\
\end{array}$ & $(0.4,0.5,0.667)$ & $\begin{array}{l}0.5,0.667,1) \\
\end{array}$ & $(0.667,1,2)$ & $(1,1.5,2)$ & $\begin{array}{l}0.5,0.667,1) \\
\end{array}$ & $(1,1,1)$ & $(0.5,1,1.5)$ & $(0.5,1,1.5)$ & $\begin{array}{l}(0.5,0.667,1) \\
\end{array}$ & $(0.4,0.5,0.667)$ & $(0.035,0.049,0.073)$ \\
\hline F15 & $(0.5,0.667,1)$ & $(0.667,1,2)$ & $(0.667,1,2)$ & $(0.5,0.667,1)$ & $(1.5,2,2,5)$ & $(0.4,0.5,0.667)$ & $(0.5,1,1.5)$ & $(1,1.5,2)$ & $(1,1.5,2)$ & $(0.5,0.667,1)$ & $(0.667,1,2)$ & $(1,1,1)$ & $(1,1.5,2)$ & $(1,1.5,2)$ & $(0.5,1,1.5)$ & $(0.046,0.067,0.098)$ \\
\hline F16 & $(0.667,1,2)$ & $(0.667,1,2)$ & $\begin{array}{l}0.5,0.667,1) \\
\end{array}$ & $(0.667,1,2)$ & $(2,2.5,3)$ & $\begin{array}{l}0.5,0.667,1) \\
\end{array}$ & $(0.667,1,2)$ & $(0.667,1,2)$ & $(0.5,0.667,1)$ & $(0.5,0.667,1)$ & $(0.667,1,2)$ & $(0.5,0.667,1)$ & $(1,1,1)$ & $(0.5,0.667,1)$ & $(0.4,0.5,0.667)$ & $(0.041,0.056,0.09)$ \\
\hline F18 & $(0.4,0.5,0.667)$ & $(0.5,0.667,1)$ & $(0.333,0.4,0.5)$ & $(0.333,0.4,0.5)$ & $(0.333,0.4,0.5)$ & $(0.333,0.4,0.5)$ & $(0.667,1,2)$ & $(0.667,1,2)$ & $(0.667,1,2)$ & $(0.5,0.667,1)$ & $(1,1.5,2)$ & $(0.5,0.667,1)$ & $(1,1.5,2)$ & $(1,1,1)$ & $(0.5,0.667,1)$ & $(0.035,0.046,0.066)$ \\
\hline F20 & $\begin{array}{l}(0.667,1,2) \\
\end{array}$ & $(0.667,1,2)$ & $(0.667,1,2)$ & $(0.5,0.667,1)$ & $(0.5,1,1.5)$ & $(0.5,0.667,1)$ & $(0.667,1,2)$ & $(1,1.5,2)$ & $(1,1.5,2)$ & $(0.4,0.5,0.667)$ & $(1.5,2,2.5)$ & $\begin{array}{l}(0.667,1,2) \\
\end{array}$ & $(1.5,2,2.5)$ & $(1,1.5,2)$ & $(1,1,1)$ & $(0.049,0.07,0.106)$ \\
\hline
\end{tabular}

Table 5. The Principal Eigenvectors matrix

\begin{tabular}{|c|c|c|c|c|c|c|c|c|c|c|c|c|c|c|c|}
\hline & F1 & F3 & F4 & F5 & F6 & F7 & F8 & F10 & F11 & F12 & F14 & F15 & F16 & F18 & F20 \\
\hline F1 & $(0.5,0.5,0.5)$ & $(0,0,0)$ & $(0.102,0.124,0.163)$ & $(0.072,0.099,0.134)$ & $(0,0,0)$ & $(0,0,0)$ & $(0,0,0)$ & $(0,0,0)$ & $(0,0,0)$ & $(0,0,0)$ & $(0,0,0)$ & $(0,0,0)$ & $(0,0,0)$ & $(0,0,0)$ & $(0,0,0)$ \\
\hline F3 & $(0,0,0)$ & $(0.5,0.5,0.5)$ & $(0.129,0.163,0.205)$ & $(0.102,0.134,0.171)$ & $(0,0,0)$ & $(0,0,0)$ & $(0,0,0)$ & $(0,0,0)$ & $(0,0,0)$ & $(0,0,0)$ & $(0,0,0)$ & $(0,0,0)$ & $(0,0,0)$ & $(0,0,0)$ & $(0,0,0)$ \\
\hline F4 & $(0.245,0.3,0.346)$ & $(0.245,0.3,0.346)$ & $(0.5,0.5,0.5)$ & $(0.134,0.176,0.215)$ & $(0,0,0)$ & $(0,0,0)$ & $(0,0,0)$ & $(0,0,0)$ & $(0,0,0)$ & $(0,0,0)$ & $(0,0,0)$ & $(0,0,0)$ & $(0,0,0)$ & $(0,0,0)$ & $(0,0,0)$ \\
\hline F5 & $(0.173,0.2,0.245)$ & $(0.173,0.2,0.245)$ & $(0.163,0.213,0.258)$ & $(0.5,0.5,0.5)$ & $(0,0,0)$ & $(0,0,0)$ & $(0,0,0)$ & $(0,0,0)$ & $(0,0,0)$ & $(0,0,0)$ & $(0,0,0)$ & $(0,0,0)$ & $(0,0,0)$ & $(0,0,0)$ & $(0,0,0)$ \\
\hline F6 & $(0,0,0)$ & $(0,0,0)$ & $(0,0,0)$ & $(0,0,0)$ & $(1,1,1)$ & $(0.245,0.3,0.346)$ & $(0,0,0)$ & $(0,0,0)$ & $(0,0,0)$ & $(0,0,0)$ & $(0,0,0)$ & $(0,0,0)$ & $(0,0,0)$ & $(0,0,0)$ & $(0,0,0)$ \\
\hline F7 & $(0,0,0)$ & $(0,0,0)$ & $(0,0,0)$ & $(0,0,0)$ & $(0,0,0)$ & $(0.5,0.5,0.5)$ & $(0,0,0)$ & $(0,0,0)$ & $(0,0,0)$ & $(0,0,0)$ & $(0,0,0)$ & $(0,0,0)$ & $(0,0,0)$ & $(0,0,0)$ & $(0,0,0)$ \\
\hline F8 & $(0,0,0)$ & $(0,0,0)$ & $(0,0,0)$ & $(0.073,0.092,0.13)$ & $(0,0,0)$ & $(0,0,0)$ & $(1,1,1)$ & $(0,0,0)$ & $(0,0,0)$ & $(0,0,0)$ & $(0,0,0)$ & $(0,0,0)$ & $(0,0,0)$ & $(0,0,0)$ & $(0,0,0)$ \\
\hline F10 & $(0,0,0)$ & $(0,0,0)$ & $(0,0,0)$ & $(0,0,0)$ & $(0,0,0)$ & $(0,0,0)$ & $(0,0,0)$ & $(1,1,1)$ & $(0,0,0)$ & $(0,0,0)$ & $(0,0,0)$ & $(0,0,0)$ & $(0,0,0)$ & $(0,0,0)$ & $(0,0,0)$ \\
\hline F11 & $(0,0,0)$ & $(0,0,0)$ & $(0,0,0)$ & $(0,0,0)$ & $(0,0,0)$ & $(0,0,0)$ & $(0,0,0)$ & $(0,0,0)$ & $(1,1,1)$ & $(0.173,0.2,0.245)$ & $(0,0,0)$ & $(0,0,0)$ & $(0,0,0)$ & $(0,0,0)$ & $(0,0,0)$ \\
\hline F12 & $(0,0,0)$ & $(0,0,0)$ & $(0,0,0)$ & $(0,0,0)$ & $(0,0,0)$ & $(0,0,0)$ & $(0,0,0)$ & $(0,0,0)$ & $(0,0,0)$ & $(0.5,0.5,0.5)$ & $(0,0,0)$ & $(0,0,0)$ & $(0,0,0)$ & $(0,0,0)$ & $(0,0,0)$ \\
\hline F14 & $(0,0,0)$ & $(0,0,0)$ & $(0,0,0)$ & $(0,0,0)$ & $(0,0,0)$ & $(0,0,0)$ & $(0,0,0)$ & $(0,0,0)$ & $(0,0,0)$ & $(0,0,0)$ & $(1,1,1)$ & $(0,0,0)$ & $(0,0,0)$ & $(0,0,0)$ & $(0,0,0)$ \\
\hline F15 & $(0,0,0)$ & $(0,0,0)$ & $(0,0,0)$ & $(0,0,0)$ & $(0,0,0)$ & $(0,0,0)$ & $(0,0,0)$ & $(0,0,0)$ & $(0,0,0)$ & $(0,0,0)$ & $(0,0,0)$ & $(1,1,1)$ & $(0,0,0)$ & $(0,0,0)$ & $(0,0,0)$ \\
\hline F16 & $(0,0,0)$ & $(0,0,0)$ & $(0,0,0)$ & $(0,0,0)$ & $(0,0,0)$ & $(0,0,0)$ & $(0,0,0)$ & $(0,0,0)$ & $(0,0,0)$ & $(0,0,0)$ & $(0,0,0)$ & $(0,0,0)$ & $(1,1,1)$ & $(0,0,0)$ & $(0,0,0)$ \\
\hline F18 & $(0,0,0)$ & $(0,0,0)$ & $(0,0,0)$ & $(0,0,0)$ & $(0,0,0)$ & $(0.173,0.2,0.245)$ & $(0,0,0)$ & $(0,0,0)$ & $(0,0,0)$ & $(0,0,0)$ & $(0,0,0)$ & $(0,0,0)$ & $(0,0,0)$ & $(1,1,1)$ & $(0,0,0)$ \\
\hline F20 & $(0,0,0)$ & $(0,0,0)$ & $(0,0,0)$ & $(0,0,0)$ & $(0,0,0)$ & $(0,0,0)$ & $(0,0,0)$ & $(0,0,0)$ & $(0,0,0)$ & $(0.245,0.3,0.346)$ & $(0,0,0)$ & $(0,0,0)$ & $(0,0,0)$ & $(0,0,0)$ & $(1,1,1)$ \\
\hline
\end{tabular}


Table 6. The final sorted weights of the CSFs.

\begin{tabular}{cccc}
\hline No. & Symbol & Final Fuzzy Weight & $\begin{array}{c}\text { The Final Weight of } \\
\text { Items }\end{array}$ \\
\hline 1 & F4 & $(0.068,0.112,0.163)$ & 0.113 \\
2 & F5 & $(0.062,0.1,0.147)$ & 0.101 \\
3 & F20 & $(0.06,0.089,0.136)$ & 0.092 \\
4 & F6 & $(0.053,0.076,0.113)$ & 0.078 \\
5 & F11 & $(0.046,0.069,0.102)$ & 0.07 \\
6 & F3 & $(0.039,0.067,0.1)$ & 0.068 \\
7 & F15 & $(0.046,0.067,0.098)$ & 0.068 \\
8 & F8 & $(0.042,0.064,0.101)$ & 0.066 \\
9 & F10 & $(0.042,0.063,0.094)$ & 0.065 \\
10 & F18 & $(0.044,0.062,0.093)$ & 0.064 \\
11 & F1 & $(0.035,0.058,0.087)$ & 0.059 \\
12 & F16 & $(0.041,0.056,0.09)$ & 0.059 \\
13 & F14 & $(0.035,0.049,0.073)$ & 0.051 \\
14 & F7 & $(0.027,0.039,0.054)$ & 0.04 \\
15 & F12 & $(0.022,0.031,0.043)$ & 0.032 \\
\hline
\end{tabular}

According to Table 6, it can be concluded that the most important factors are formulated in Figure 4. Most of these items are discussed in other improvement projects, such as the variation of CSFs with different degrees of importance. The key to building a successful RCM project starts with a pre-implementation phase. In this phase, some questions that need to be answered are: How much it costs? Do we have the necessary resources? Who will be responsible for leading the effort? Do the manager and staff have sufficient knowledge about RCM? How do you manage the implementation of RCM tasks? Who will be involved? The spirit of employees' cooperation before the implementation of RCM also needs to be increased to support the success of RCM pre-implementation.

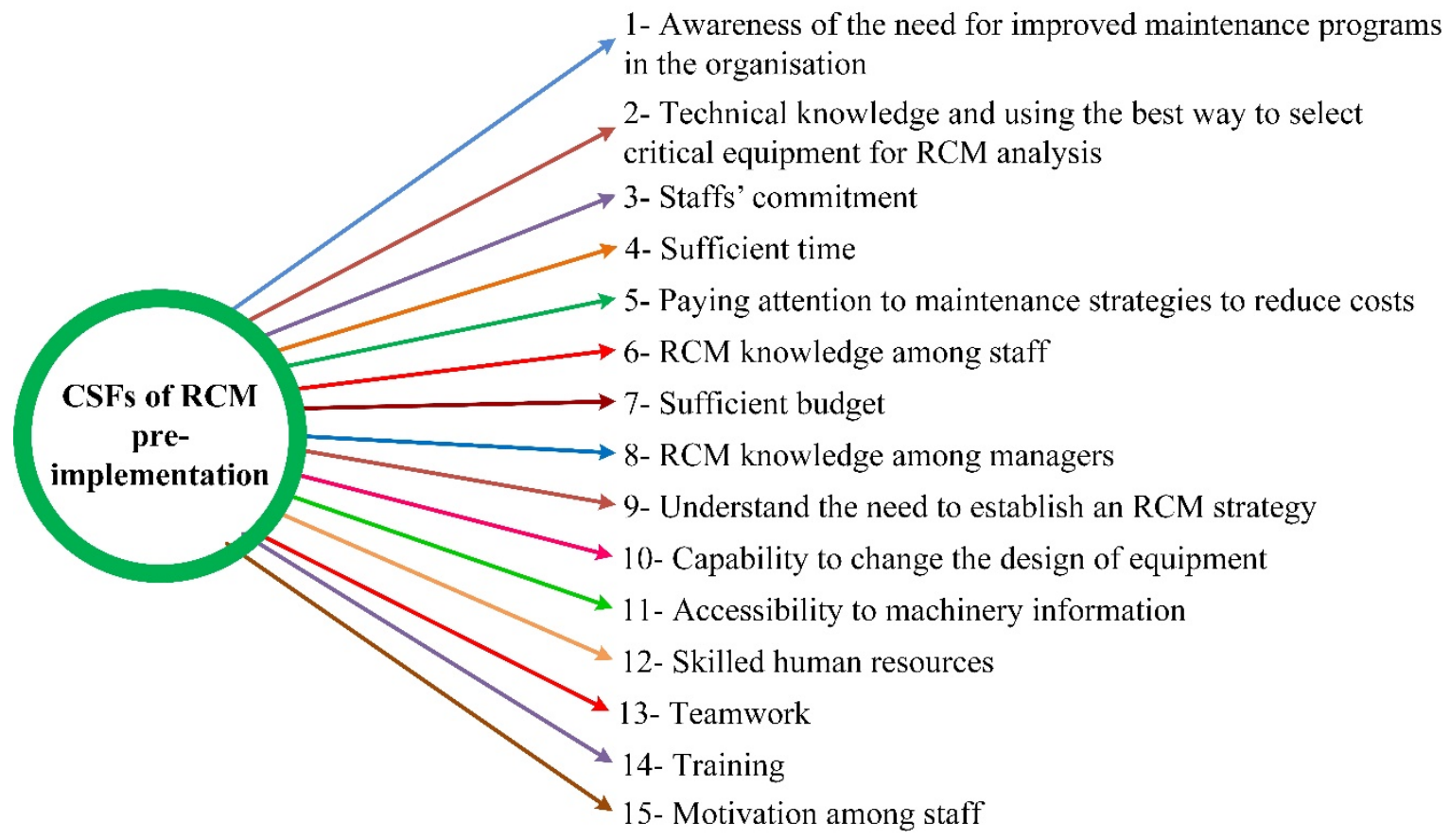

Figure 4. The prioritised CSFs of RCM in the pre-implementation phase.

\section{Conclusions}

A nominal group technique has been applied as a general methodology in this study. This method involves two main processes: (i) Determination of the CSFs using expert's group discussion, and (ii) 
Prioritising the determining factors using Fuzzy ANP. As a result, fifteen success factors are important to be considered by organisations before they implement the RCM. Awareness of the need for improved maintenance programs in the organisation was classed as the highest priority, with a final weight of 0.113 , followed by technical knowledge and using the best way to select critical equipment for RCM analysis, with a final weight of 0.101 . The third priority is staffs' commitment with a final weight of 0.092. The fourth priority is sufficient time, with a final weight of 0.078 . The fifth priority is paying attention to maintenance strategies to reduce costs, with a final weight of 0.07 . The sixth and seventh priorities are sequentially placed by RCM knowledge among staff and a sufficient budget, which received a similar final weight of 0.068 . The eighth priority is RCM knowledge among managers, with a final weight of 0.066 . The ninth priority is understanding the need to establish an RCM strategy, with a final weight of 0.065 . The tenth priority is the capability to change the design of equipment, with a final weight of 0.064 . The eleventh and twelfth priorities are consecutively represented by accessibility to machinery information and skilled human resources, with similar final weights of 0.059 . The thirteenth priority is teamwork, with a final weight of 0.051 . The fifteenth priority is training, with a final weight of 0.04 . The lowest priority is the motivation among staff, with a final weight of 0.032 .

This study contributes to both theoretical development and practice. From an academic point of view, this study would advance the growth of RCM research by filling the knowledge gap in the related topic. The method used in this study, namely the nominal group approach, is still rarely applied for determining the CSFs. From a practical perspective, the identification of CSFs is useful for maintaining strategic planning efforts. They are important for organisations to avoid and mitigate unpredictable problems that emerge during RCM implementation. These CSFs would improve the strategic analysis and thinking required to implement RCM effectively. The framework proposed here can be applied as a decision support system for senior managers and practitioners involved in maintenance strategies. This paper contributes to existing knowledge as it provides an objective approach for practitioners to focus on the most critical factors and improve overall performance by progressively considering the identified CSFs.

This study was carried out by considering the characteristics of oil and gas organisations, which emphasises on improving the reliability of refineries. Petrochemical industries are classified as high-risk companies with a dire need for cost management, where prices are very flexible and vulnerable to changes in supply and demand. Their components are toxic, explosive, and flammable, so it is necessary to have a systematic maintenance program to ensure safety and consistency cost-effectiveness. This program can be further extended to other industries, such as manufacturing, through the application of additional criteria. Customising, according to the circumstances of the situations, the identified CSFs and the proposed framework, can be applied in other industries, particularly in developing countries. The CSFs ranking is distinctive for each country and, therefore, the outcomes of the present study cannot be directly applied to other countries. The CSF ranking also varies from one country to another, even the priority o each CSF may change over time.

Further studies need to be done to advance the results of this study. A study proposing a strategic planning process with the identified CSFs that culminate the development of an integrated strategic planning framework for the implementation of RCM would be valuable for the manufacturing organisations. It would provide some holistic strategic plans that describe the current status of organisations, targets, goals for the future, and approaches for going forward.

Author Contributions: M.Z.: Developing the methodology, investigation, writing the manuscript. A.G.C.: Developing the first draft, developing the methodology, manuscript checking and editing. F.A.G.: Extending the methodology, writing the manuscript. J.J.K.: Project supervision and coordination, funding acquisition, adjusting the methodology, manuscript checking and editing. All authors have read and agreed to the published version of the manuscript. 
Funding: This research has been supported by the EU project "Sustainable Process Integration Laboratory-SPIL", project No. CZ.02.1.01/0.0/0.0/15_003/0000456 funded by EU “CZ Operational Programme Research, Development and Education", Priority 1: Strengthening capacity for quality research.

Conflicts of Interest: The authors declare no conflict of interest.

\section{References}

1. Chofreh, A.G.; Goni, F.A.; Klemeš, J.J. Development of a framework for the implementation of sustainable enterprise resource planning. Chem. Eng. Trans. 2017, 61, 1543-1548. [CrossRef]

2. Gupta, G.; Mishra, R. Identification of Critical Components Using ANP for Implementation of Reliability Centered Maintenance. Procedia CIRP 2018, 69, 905-909. [CrossRef]

3. Zahedi-Hosseini, F.; Scarf, P.; Syntetos, A. Joint Optimization of Inspection Maintenance and Spare Parts Provisioning: A Comparative Study of Inventory Policies using Simulation and Survey Data. Reliab. Eng. Syst. Saf. 2017, 168, 306-316. [CrossRef]

4. Nourelfath, M.; Nahas, N.; Ben-Daya, M. Integrated preventive maintenance and production decisions for imperfect processes. Reliab. Eng. Syst. Saf. 2016, 148, 21-31. [CrossRef]

5. Consilvio, A.; Di Febbraro, A.; Sacco, N.; Alice, C. A modular model to schedule predictive railway maintenance operations. In Proceedings of the 2015 International Conference on Models and Technologies for Intelligent Transportation Systems (MT-ITS), Budapest, Hungary, 3-5 June 2015; Institute of Electrical and Electronics Engineers (IEEE): Budapest, Hungary, 2015; pp. 426-433.

6. Petrovic, D.; Tanasijević, M.L.; Stojadinović, S.; Ivaz, J.; Stojković, P. Fuzzy Model for Risk Assessment of Machinery Failures. Symmetry 2020, 12, 525. [CrossRef]

7. Wang, Y.; Liu, Y.; Chen, J.; Li, X. Reliability and condition-based maintenance modeling for systems operating under performance-based contracting. Comput. Ind. Eng. 2020, 142, 106344. [CrossRef]

8. Ma, X.; Liu, B.; Yang, L.; Peng, R.; Zhang, X. Reliability analysis and condition-based maintenance optimisation for a warm standby cooling system. Reliab. Eng. Syst. Saf. 2020, 193, 106588. [CrossRef]

9. Karar, A.N. Reliability Centered Maintenance Quality in Oil and Gas Field: Guidelines to Improve your RCM Quality; LAP LAMBERT Academic Publishing: Düsseldorf, Germany, 2016; ISBN1 10: 3659918741. ISBN2 13: 978-3659918742.

10. Chofreh, A.G.; Goni, F.A.; Zeinalnezhad, M.; Navidar, S.; Shayestehzadeh, H.; Klemeš, J.J. Value chain mapping of the water and sewage treatment to contribute to sustainability. J. Environ. Manag. 2019, 239, 38-47. [CrossRef] [PubMed]

11. Zeinalnezhad, M.; Chofreh, A.G.; Goni, F.A.; Klemeš, J.J. Air pollution prediction using semi-experimental regression model and Adaptive Neuro-Fuzzy Inference System. J. Clean. Prod. 2020, 261, 121218. [CrossRef]

12. Plucknette, D. RCM Implementation 2017. Available online: https://reliabilityweb.com/articles/entry/rcm implementation/ (accessed on 26 February 2020).

13. Zakikhani, K.; Nasiri, F.; Zayed, T. Availability-based reliability-centered maintenance planning for gas transmission pipelines. Int. J. Press. Vessel. Pip. 2020, 183, 104105. [CrossRef]

14. Tang, Y.; Liu, Q.; Jing, J.; Yang, Y.; Zou, Z. A framework for identification of maintenance significant items in reliability centered maintenance. Energy 2017, 118, 1295-1303. [CrossRef]

15. Rahmati, S.H.A.; Ahmadi, A.; Karimi, B. Multi-objective evolutionary simulation based optimisation mechanism for a novel stochastic reliability centered maintenance problem. Swarm Evol. Comput. 2018, 40, 255-271. [CrossRef]

16. Rashedi-Owlia, H.; Hoseininasab, H.; Zaree-Mehrjerdi, Y. Application of RCM to enhance the efficiency and effectiveness maintenance process (case study: Oil and gas production, South Zagros company of Iran). Sharif J. Ind. Eng. Manag. 2012, 28, 2.

17. Borjalilu, N.; Ghambari, M. Optimal maintenance strategy selection based on a fuzzy analytical network process: A case study on a 5-MW powerhouse. Int. J. Eng. Bus. Manag. 2018, 10, 1847979018776172. [CrossRef]

18. Zeinalnezhad, M.; Chofreh, A.G.; Goni, F.A.; Klemeš, J.J.; Darvishvand, A.M.; Vashaghi, K. Forecasting air pollution by adaptive neuro fuzzy inference system. In Proceedings of the 4 th International Conference on Smart and Sustainable Technologies (SpliTech), Split, Croatia, 18-21 June 2019; pp. 1-3.

19. Xu, G.; Hou, D.; Qi, H.; Bo, L. High-speed train wheel set bearing fault diagnosis and prognostics: A new prognostic model based on extendable useful life. Mech. Syst. Signal Process. 2021, 146, 107050. [CrossRef] 
20. Afzali, P.; Keynia, F.; Rashidinejad, M. A new model for reliability-centered maintenance prioritisation of distribution feeders. Energy 2019, 171, 701-709. [CrossRef]

21. Alvarez-Alvarado, M.; Jayaweera, D. Operational risk assessment with smart maintenance of power generators. Int. J. Electr. Power Energy Syst. 2020, 117, 105671. [CrossRef]

22. Piasson, D.; Bíscaro, A.A.; Leão, F.B.; Mantovani, J.R.S. A New Approach for Reliability-Centered Maintenance Programs in Electric Power Distribution Systems based on a Multi objective Genetic Algorithm. Electr. Power Syst. Res. 2016, 137, 41-50. [CrossRef]

23. Yssaad, B.; Abene, A. Rational Reliability Centered Maintenance Optimization for power distribution systems. Int. J. Electr. Power Energy Syst. 2015, 73, 350-360. [CrossRef]

24. Piechnicki, F.; Loures, E.; Santos, E. A Conceptual Framework of Knowledge Conciliation to Decision Making Support in RCM Deployment. Procedia Manuf. 2017, 11, 1135-1144. [CrossRef]

25. Ma, Z.; Ren, Y.; Xiang, X.; Turk, Z. Data-driven decision-making for equipment maintenance. Autom. Constr. 2020, 112, 103103.

26. Erguido, A.; Márquez, A.C.; Castellano, E.; Flores, J.; Fernández, J.G. Reliability-based advanced maintenance modelling to enhance rolling stock manufacturers' objectives. Comput. Ind. Eng. 2020, 144, 106436. [CrossRef]

27. Yavuz, O.; Doğan, E.; Carus, E.; Görgülü, A. Reliability Centered Maintenance Practices in Food Industry. Procedia Comput. Sci. 2019, 158, 227-234. [CrossRef]

28. Zhao, B.; Chen, H.; Gao, D.; Xu, L. Risk assessment of refinery unit maintenance based on fuzzy second generation curvelet neural network. Alex. Eng. J. 2020, 59, 1823-1831. [CrossRef]

29. Jaderi, F.; Ibrahim, Z.Z.; Zahiri, M.R. Criticality Analysis of Petrochemical Assets using Risk Based Maintenance and the Fuzzy Inference System. Process Saf. Environ. Prot. 2019, 121, 312-325. [CrossRef]

30. Ceptureanu, E.G.; Ceptureanu, S.I.; Violeta, R.; Ionescu, S.A. What Makes Coopetition Successful? An Inter-Organizational Side Analysis on Coopetition Critical Success Factors in Oil and Gas Distribution Networks. Energies 2018, 11, 3447. [CrossRef]

31. Zhao, Z.; Xiao, B.; Wang, N.; Yan, X.; Ma, L. Selective Maintenance Optimization for a Multi-State System Considering Human Reliability. Symmetry 2019, 11, 652. [CrossRef]

32. Søndergaard, E.; Ertmann, R.K.; Reventlow, S.; Lykke, K. Using a modified nominal group technique to develop general practice. BMC Fam. Pr. 2018, 19, 117. [CrossRef]

33. Chofreh, A.G.; Goni, F.A.; Shaharoun, A.M.; Ismail, S. Review on enterprise resource planning implementation roadmap: Project management perspective. Sains Humanika 2014, 2, 135-138.

34. Sadeghi-Sefidmazgi, A.; Nejati-Javaremi, A.; Moradi-Shahrbabak, M.; Miraei-Ashtiani, S.R.; Amer, P.R. Economic values under inappropriate normal distribution assumptions. Animal 2012, 6, 1225-1230.

35. Gogus, O.; Boucher, T.O. Strong transitivity, rationality and weak monotonicity in fuzzy pairwise comparisons. Fuzzy Sets Syst. 1998, 94, 133-144. [CrossRef]

36. Asan, U.; Soyer, A.; Serdarasan, S. A Fuzzy Analytic Network Process Approach. In Computational Intelligence Systems in Industrial Engineering; Atlantis Press: Paris, France, 2012; pp. 155-179.

(C) 2020 by the authors. Licensee MDPI, Basel, Switzerland. This article is an open access article distributed under the terms and conditions of the Creative Commons Attribution (CC BY) license (http://creativecommons.org/licenses/by/4.0/). 